\title{
Acute right ventricular infarction
}

\author{
Early diagnosis may be difficult but saves lives
}

Recognition and management of right ventricular infarction reduce the morbidity and mortality in cardiogenic shock.' Postmortem studies have shown that the right ventricle is commonly affected in myocardial infarction ${ }^{2}$ but dominant right ventricular dysfunction is uncommon; left ventricular dysfunction usually predominates. Right ventricular infarction almost always occurs with occlusion of the right coronary artery and is associated with inferior infarction. ${ }^{3} \mathrm{~A}$ patient with cardiogenic shock and inferior infarction who has increased central venous pressure, a positive Kussmaul's sign, and clear lung fields may well have right ventricular infarction whereas this is most unlikely in anterior infarction. ${ }^{+}$ Patients with right ventricular infarction are often treated paradoxically: diuretics are stopped, although the patients may have oliguria; nitrates are stopped, although the patients may have acute ischaemia; and large volumes of fluid are used in patients with increased venous pressure.

Unless the right ventricle is hypertrophic from another cause the changes in the electrocardiogram are often subtle after right ventricular infarction. ${ }^{5}$ Elevation of the ST segment in lead V4R is both sensitive and specific for right ventricular infarction, and this lead should be recorded in all patients with inferior infarction. ${ }^{6}$

The most important advance in recognising and treating right ventricular infarction is haemodynamic monitoring with pulmonary artery catheters. ${ }^{7}$ Most patients with right ventricular infarction have increased right atrial pressure and a ratio of right atrial to pulmonary wedge pressure of greater than $0 \cdot 86 .^{8} \mathrm{~A}$ low or normal wedge pressure in a patient with a low cardiac output after inferior infarction should always alert the doctor to the possibility of right ventricular infarction.

Radionuclide ventriculography may show right ventricular dysfunction and dilatation and abnormalities in the motion of the ventricular wall. ${ }^{910}$ Infarct scintigraphy seems to be sensitive but not specific for right ventricular damage. ${ }^{11}$ Echocardiography may show right ventricular hypokinesis, and changes in the relative pressures of the right and left ventricles may be reflected by flattening of the interventricular septum. ${ }^{12}$

The most important step in treating right ventricular infarction is to confirm the diagnosis early. If this is done the patient should recover. ${ }^{1}$ A pulmonary artery catheter should be inserted in any patient who has cardiogenic shock after a myocardial infarction, especially if there is no pulmonary congestion. The central venous pressure is inaccurate in assessing left ventricular filling pressure, and treatment based on this alone may be dangerous. ${ }^{13}$ The first step in treatment is to avoid agents that reduce ventricular preload-namely, diuretics, nitrates, nitroprusside, and narcotics. If the patient requires pain relief non-narcotic agents should be used first, and if narcotics are needed small frequent doses should be used to minimise their haemodynamic effects. ${ }^{14}$

For years the mainstay of treatment was volume expansion alone. ${ }^{7}$ Rapid infusion of colloid solutions may increase left ventricular filling pressures and cardiac output. But both right and left ventricular filling pressures will be augmented, and right ventricular dilatation may occur ${ }^{15}-$ possibly impairing left ventricular filling and hence systolic function. ${ }^{1617}$ If the cardiac output fails to increase in response to volume infusions inotropic agents are indicated-and dobutamine is probably the best. ${ }^{1318}$ It tends to increase cardiac output without increasing pulmonary artery pressure. ${ }^{19}$ This is particularly important as pulmonary artery pressure reflects right ventricular afterload. The right ventricle is sensitive to increase in afterload and will dilate and fail, ${ }^{16}$ which may lead to impairment of left ventricular filling and output.

If the patients have left ventricular dysfunction they may already have appreciably increased pulmonary artery pressure. Any increase in right ventricular diastolic pressure and volume will cause intrapericardial pressures to rise, leading to increases in left ventricular filling pressure without increases in volume. ${ }^{20}$ Thus a vicious cycle of progressive right and left ventricular dysfunction leads to a catastrophic fall in cardiac output. In these circumstances it may be necessary to "unload" the left ventricle using a combination of the arterial vasodilatation of nitroprusside and inotropic effect of dobutamine. ${ }^{21}$ Great care has to be taken to minimise the venodilator effects of nitroprusside, which may of course worsen the patient's condition. It may be necessary to use intra-aortic balloon counterpulsation to reduce left ventricular afterload without affecting preload.

Arrhythmias associated with right ventricular infarction need active treatment, and ventricular arrhythmias related to complete heart block may demand sequential atrioventricular pacing..$^{22}$ Rare complications of right ventricular infarction include right ventricular rupture,,$^{23}$ ventricular septal defect, ${ }^{24}$ shunting across an atrial septal defect or patent foramen ovale, ${ }^{25}$ papillary muscle rupture,${ }^{26}$ and pulmonary emboli. ${ }^{27}$

In conclusion, acute right ventricular infarction should be considered in all patients with cardiogenic shock after myocardial infarction. It requires haemodynamic monitoring 
and intensive treatment. If the condition is diagnosed early and treated appropriately the prognosis is much better than that in patients with cardiogenic shock caused predominantly by left ventricular dysfunction. ${ }^{28} 29$

Clinical Research Fellow in Cardiology,

J L CAPLIN

Cardiac Unit,

Massachusetts General Hospital,

Boston,

MA 02114, United States

1 Wilson BC, Cohn JN. Right ventricular infarction: clinical and pathophysiologic considerations. Ann Intern Med 1988;33:295-310.

2 Ratliff NB, Hackel DB. Combined right and left ventricular infarction: pathogenesis and clinicopathologic correlations. Am f Cardiol 1980;45:217-21.

3 Shah PK, Maddahi J, Berman DS, Pichler M, Swan HJC. Scintigraphically detected predominant right ventricular dysfunction in acute myocardial infarction: clinical and hemodynamic right ventricular dysfunction in acute myocardial infarction: clinical and hemodyna

4 Dell'Italia LJ, Starling MR, O'Rourke RA. Physical examination for exclusion of hemodynamically important right ventricular infarction. Ann Intern Med 1983;99:608-11.

5 Andersen HR, Neilson D, Falk E. Right ventricular infarction: diagnostic value of ST elevation in lead III exceeding that of lead II during inferior/posterior infarction and comparison of right chest leads V3R to V7R. Am Heart f 1989;117:82-6.

6 Lopez-Sendon J, Coma-Canella I, Alcasena S, Seoane J, Gamello C. Electrocardiographic findings in acute right ventricular infarction: sensitivity and specificity of electrocardiographic alterations in right precordial leads V4R, V3R, V1, V2 and V3. $\mathcal{~ A m ~ C o l l ~ C a r d i o l ~ 1 9 8 5 ; 6 : 1 2 7 3 - 9 . ~}$

7 Cohn JN, Guiha NH, Broder MI, Lima CJ. Right ventricular infarction. Clinical and hemodynamic features. Am f Cardiol 1974;33:209-14.

8 Lopez-Sendon J, Coma-Canella I, Gammallo C. Sensitivity and specificity of hemodynamic criteria in the diagnosis of acute right ventricular infarction. Circulation 1981;64:515-26.

9 Caplin JL, Dymond DS, Flatman WD, Spurrell RAJ. Global and regional right ventricular function after acute myocardial infarction: dependence upon the site of left ventricular infarction. Br Heart $f$ 1987;58:101-9.

10 Rigo P, Murray M, Taylor DR, et al. Right ventricular dysfunction detected by gated scintiphotography in patients with acute inferior myocardial infarction. Circulation 1975;52: 268-74.

11 Wackers FJT, Lie KS, Sokele EB, Res J, van der Schoot JB, Durrer D. Prevalence of right ventricular involvement in inferior wall infarction assessed with myocardial imaging with thallium 201 and technetium 99m pyrophosphate. Am $\mathcal{J}$ Cardiol 1978;42:358-62.
12 Bellamy GR, Rasmussen HH, Nasser FN, Wiseman JC, Cooper RA. Value of two-dimensional echocardiography, electrocardiography and clinical signs in detecting right ventricular infarction. Am Heart I 1986;112:304-9.

13 Clark G, Strauss HD, Roberts R. Dobutamine vs furusemide in the treatment of cardiac failure due to right ventricular infarction. Chest 1980;77:220-3.

$14 \mathrm{Jaffe} \mathrm{JH}$, Martin WR. Narcotic analgesics and antagonists. In: Goodman LS, Gilman A, eds. Goodman and Gilman's, the pharmacological basis of therapeutics. 5th ed. New York: MacMillan Goodman and Gilman's,

15 Goldstein JA, Vlahakes GJ, Verrier ED, et al. Volume loading improves low cardiac output in experimental right ventricular infarction. $f$ Am Coll Cardiol 1983;2:270-8.

16 Lorell B, Palacios I, Daggett WM, Jacobs ML, Fowler BN, Newell JB. Right ventricula distention and left ventricular compliance. Am $\mathcal{F}$ Physiol 1981;240:H87-98.

17 Elzinga G, van Grondell R, Westerhof N, van den Bos GC. Ventricular interference. Am $\mathcal{F}$ Physiol 1974;226:941-7.

18 Dell'Italla LJ, Starling MR, Blumhardt R, Lasher JC, O'Rourke RA. Comparative effects of volume loading, dobutamine and nitroprusside on patients with predominant right ventricular infarction. Circulation 1985;72:1327-35.

19 Gillespie TA, Ambos HD, Sobel BE, Roberts R. Effects of dobutamine in patients with acute myocardial infarction. Am $\mathcal{J}$ Cardiol 1977;39:588-94.

20 Goldstein JA, Vlahakes GJ, Verrier ED, et al. The role of right ventricular systolic dysfunction and elevated intrapericardial pressure in the genesis of low cardiac output in experimental right elevated intrapericardial pressure in the genesis of
ventricular infarction. Circulation 1982;65:513-22.

21 Yin FPC, Guzman PA, Brin KP, et al. Effect of nitroprusside on hydraulic vascular loads on the right and left ventricle of patients with heart failure. Circulation 1983;66:1330-9.

22 Love JC, Hafferjee CI, Gore JM, Alpert JS. Reversibility of hypotension and shock by atrial or atrioventricular sequential pacing in patients with right ventricular infarction. Am Heart $f$ 1984;108:5-13.

23 Shires DB. Rupture of the right ventricle. JAMA 1968;203:888-90.

24 Higgin SG. Rupture of interventricular septum and right ventricle after acute myocardia infarction. Aust NZ F Med 1981;11:46-7.

25 Reitveld AP, Merrman L, Essed CE, Trimbos JBMJ, Hegemeijer F. Right to left shunt, with severe hypoxemia, at the atrial level in a patient with hemodynamically important righ ventricular infarction. $\mathcal{f} \mathrm{Am}$ Coll Cardiol 1983;2:776-9.

26 Lader E, Colvin S, Tunick P. Myocardial infarction complicated by rupture of both ventricular septum and right ventricular papillary muscle. Am $\mathcal{C}$ Cardiol 1983;52:423-4.

27 Stowers SA, Leiboff RH, Wasserman AG, Katz RJ, Bren GB, Hsu I. Right ventricular thrombus formation associated with acute myocardial infarction: diagnosis by 2 dimensional echocardiography. Am J Cardiol 1983;52:912-3.

28 Brown KA, DeSanctis RW, DiCola V, Boucher CA, Pohost GM, Okada RD. Long term exercise and hemodynamic follow-up in patients with previous right ventricular myocardial infarction. Am Heart $\mathcal{O}$ 1986;112:1321-2.

29 Leinbach RC, DeSanctis RW, Goldman R. Shock, cardiac arrest and orthostatic hypotension. In Eagle KA, Haber E, DeSanctis RW, Austen WG, eds. The practice of cardiology. 2nd ed. Boston, Toronto: Little, Brown, 1989:34.

\section{Non-migrainous headaches}

\section{Classification and management}

Headaches are common and are of many different types, most of them benign. Not surprisingly, different names and systems of classification abound. In an attempt to sort out the confusion the International Headache Society has produced a new set of guidelines, classifying headaches into 13 different groups (box).' (For details of migraine see next week's issue.)

Tension type headaches, which may be either episodic or chronic, are the commonest headaches and include muscle contraction headache, stress headache, essential headache, and psychogenic headache.' These types of headache typically press "like a tight hat"; the pain is mild to moderate, bilateral, and does not worsen with normal physical activity. Vomiting is unusual, but photophobia and phonophobia may occur. Headaches in this group are further subdivided into those with abnormalities of the pericranial muscles diagnosed either by palpation or by electromyographic evidence of increased muscle activity at rest and those without such abnormalities.

Treatment of tension type headaches is unsatisfactory. A detailed history with attention to symptoms of anxiety and depression should be taken and a careful examination, including palpation of the head, performed. Patients should be given an explanation of the possible mechanism of the headaches. They will commonly have received an unsympathetic hearing from their doctor; general practitioners are well placed to recognise the social and family stresses their patients may be suffering, and their support is important for the successful management of this condition. Psychotherapy, counselling, and emotional support may be of value. Psychiatric referral is likely to be rejected by many patients until other therapeutic measures have been tried. Muscle contraction headaches may also be the response to localised disease of the head, temporomandibular joint dysfunction, cervical spondylosis, eye muscle disorders, and sinus diseases, ${ }^{2}$ which should of course be treated if found.

Episodic tension headaches with a prominent muscle component may be helped by simple massage. Analgesics do not usually help, though non-steroidal anti-inflammatory drugs may be useful. ${ }^{3}$ Amitriptyline and other tricyclic drugs may non-specifically raise the pain threshold, and full doses should be given for several months in resistant cases. Adding propranolol may provide an extra therapeutic benefit. ${ }^{2}$

Treating chronic tension type headache is even more difficult. Sedative drugs such as benzodiazepines have commonly been prescribed, but these should be avoided as tolerance usually results and the problems of chronic sedative usage may emerge. Episodic use of these drugs may sometimes be helpful for severe bouts of pain. Their dose should be rapidly tailed off once the pain has been controlled. Other non-pharmacological measures should be considered. Experience in America of biofeedback techniques, behavioural programmes, and relaxation suggest that these may be helpful. ${ }^{+}$Few controlled trials have, however, been done to support these claims, and these treatments are not easily obtained in Britain.

Tension headache and migraine commonly coexist, and coding them separately in order of importance is preferable to using the term "combination headaches." Treatment is directed towards the more important of the two, though prophylaxis against migraine is easier to prescribe. 